University of Nebraska - Lincoln

DigitalCommons@University of Nebraska - Lincoln

November 1999

\title{
Executive functioning in preschool children: Performance on A- Not-B and other delayed response format tasks
}

\author{
K. A. Espy \\ University of Nebraska-Lincoln, kespy2@unl.edu \\ P. M. Kaufmann \\ M. D. McDiarmid \\ M. L. Glisky
}

Follow this and additional works at: https://digitalcommons.unl.edu/dcnlfacpub

Part of the Neurosciences Commons

Espy, K. A.; Kaufmann, P. M.; McDiarmid, M. D.; and Glisky, M. L., "Executive functioning in preschool children: Performance on A-Not-B and other delayed response format tasks" (1999). Developmental Cognitive Neuroscience Laboratory - Faculty and Staff Publications. 22.

https://digitalcommons.unl.edu/dcnlfacpub/22

This Article is brought to you for free and open access by the Developmental Cognitive Neuroscience Laboratory at DigitalCommons@University of Nebraska - Lincoln. It has been accepted for inclusion in Developmental Cognitive Neuroscience Laboratory - Faculty and Staff Publications by an authorized administrator of DigitalCommons@University of Nebraska - Lincoln. 
The A-not-B task ( $A B$ ) has been used extensively to inve gateognitive development in infants (Wellman, Cross, \& Bartsch, 1986) \%n the classic $A B$ task by Piaget (1954), infants observe and retrieve airowardibidden at location A for several trials. The contingency then is reverosiswith the re-

\section{Executive Functioning in Preschool Children: Performance} on A-Not-B and Other Delayed Response Format Tasks

\author{
Kimberly Andrews Espy \\ Southem Minois University School of Medicine \\ Paul M. Kaufmann \\ Clyde L. Choate Mental Health and Developmental Censer \\ Melanie D. McDiarmid \\ Southem Ilinois University School of Medicine \\ and \\ Martha L. Glisky \\ Morthwestert University Medical School \\ The A-not-B (AB) lask has ben hypothesized to measure execulize/frontal lobe \\ function; however, the developmental and measurement characteristics of this task \\ have not been investigated. Performance on AB and comparison tasks adapted from \\ developmental and ncuroscience literature was examined in 11 ? preschool children \\ (ages 23-66 months). Age significantly predicled performance on AB, Delayed Al- \\ temation, Spatial Reversal, Color Reversal, and Selr-Control tasks. A four-factor \\ analytic model best fit task performance data. $A B$ task indices loaded on two factors \\ with measures from the Self-Control and Delayed Alternation tasks, respectively. \\ AB indices did not load with those from the reversal tasks despite similarities in lask \\ administration and presumed cognitive demand (working memory). These results \\ indicale that $A B$ is sensitive to individual differences in age-related performance \\ in preschool children and suggest that $A B$ performance is related to both working \\ memory and inhibition processes in this age range. 1999 Academic Press
}

This research was supported, in part, by a granl from the University of Atizona Foundation. USESPY. The authors thank the stalT from the Beginning School, Presbyterian Child Development Center, and the Child Development Laboratory and the participating families. We also thank Dennis Molfese for comments on an earlier draft of this paper.

Correspondence concerning this article and reprint reguests should be addressed to Kimberly; Andrews Espy, Department of Psychialry, Mail Step 65.17, Southem Illinois Uniwersily School of Medicinc, Carbondale, IL, 62901-6517. E-mail: kespy@som.siu.edu. ward hidden at location B. On the reversal trial, 8-to 12-month-old infants search for the reward at location $A$, whereas those infants months correctly retrieve the reward at location $B$. Piaget:concluded that faulty object permanence was the cognitive mechanism urdedying poor $A B$ performance in the younger infant. The infant cannot mentally represent the object independently of the motoric act of retrieval on the previous trial.

AB AND BRAIN

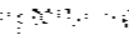

More recently, $\mathrm{AB}$ has enjoyed renewed interest because of similarity to the delayed response (DR) paradigm from the animal neuroscience literature (Diamond, 1990a). Similar perseverative error patterns on $A B$ and DR have been observed in frontally ablated adult monkeys (Diamond $\&$ GoldmanRakic, 1989), intact and frontally ablated infant monkeys (Dianond \& Goldman-Rakic, 1986), and intact 7-to 12-month-old human infants (Diamond, 1985; Diamond \& Doar, 1989). Resting frontal EEG activity and increased anterior to posterior EEG coherence (Bell \& Fox, 1992; Fox \& Bell, 1990) also discriminated successful AB performance in infants Based on the convergence of these findings, Diamond (1990a) concluded that frontal lobe maturation underlies the developmental change in $A B$ performance in late infancy. Because the relation of $A B / D R$ and dorsolateral prefrontal cortical function has been well defined (Goldman-Rakic, 1987b), these measures are considered by many researchers to represent early manifestations of executive behavior in infants.

The structure and function of the dorsolateral prefrontal cortex undergo changes in late infancy concurrently with the emergence of $A B$ performance [e.g. maximal synaptic density is achieved (Huttenlocher \& Dabholkar, 1997 ) and glucose metabolism is increased (Chugani \& Phelps, 1990)]. Substantive changes in brain organization in the prefrontal cortex also occur later, during the preschool years, including large-scale pruning of symaptic connections (Huttenlocher, 1979) and maturation of subcortical prefrontal myelination (Kinney, Brody, Kloman, \& Gilles, 1988). In:line with this finding, Thatcher and colleagues (Thatcher, 1991, 1994; Thatcher, Walker, \& Giudice, 1987) have identified a cycle of brain EEG signal development between 1 and 5 years of age. This dewelopmental cycle was characterized by increased coherence in resting EEG between the short-distance anterior and posterior electrode recording sites. Frontolateral connections were lengthened, becoming synchronous prior to frontal dorsomedial and central sites in the left hemisphere. long-distance connections in the right hemisphere were differentiated into shorter fibers, laterally to medially (Thatcher, $1991)$. 
Given the robust relation between $A B / D R$ tasks and dorsolateral prefronlal cortex, $A B$ may be sensitive to these ongoing changes in prefrontal brain areas that occur during the preschool years (Huttenlocher, 1979; Thatcher, 1994). Developmental gains in AB performance may be evident across a wider age range than originally considered by Piaget (1954). Diamond (1990a) speculated that the characteristic pattern of $A B$ perseverative errors may be elicited in older children by increasing the delay between hiding and retrieval. Diamond, Prevor, Callendar, and Druin (1997) found that the percentage correct on AB increased with age between 15 and 30 months in normal controls with a 5-s delay. Further developmental increases may be evident in older preschool children by further increasing the delay between hiding and retrieval. This premise, however, remains uninvestigated to date.

\section{AB AND COGNITION}

Although there is general agreement concerning brain-behavior relations in $A B$, various opinions persist concerning the cognitive processes that underlie $\mathrm{AB}$ performance. Diamond and Goldman-Rakic (1989) have proposed that $A B$ depends on both working memory and inhibition of a prepotent response. Working memory has been defined as "the process by which symbolic representations are accessed and held on-line to guide a response" (Goldman-Rakic, 1987b, p. 604). In infants, who have immature prefrontal cortices, this process is not considered fully functional. The location of the reward at the observed location $B$ is not maintained across the temporal delay (Fuster, 1985). Thus, the infant must rely on associative memory to find the reward and therefore searches at the previously rewarded location, A. The delay appears to be critical in order to activate working memory (GoldmanRakic, $1987 \mathrm{~b}$ ). Neither intact infants nor monkeys with prefrontal lesions err if there is no delay between hiding and retrieval where the internal representation is held "on-line" (Diamond, 1985). Several investigations have demonstrated that delay length influences AB performance. Diamond (1985) found chance performance as delay length increased, whereas Wellman et al. (1986) observed that infants made more errors at longer delays.

Diamond (1990b) compared performance on Object Retrieval (OR) and $A B$ tasks in order to investigate the component cognitive processes of $A B$ performance. In $O R$, the infant retrieves a reward from beneath a clear Plexiglas box with an opening on one side. Manual reaching is required in $O R$ and $A B$, but $O R$ performance does not depend on working memory because there is no delay and the reward is in full view. In order to obtain the reward, the infant must inhibit the tendency to reach directly at the reward (which is blocked by a clear, but solid top) and reach obliquely through the side opening. A similar pattern of developmental improvement on $O R$ and $A B$ wits observed in 6- to 12-month-old infants (Diamond, 1990b; Matthews.
Ellis, \& Nelson, 1996). Other corroborating evidence is puided by $O R$ performance of adult monkeys with dorsolateral prefrontalocticalilesions. They scratched repeatedly at the solid top and retrieved the objoct only when inadvertently looking through the open side (Diamond, 1990) :

Findings from other studies, however, do not support $A B$ and $O R$ measurement consistency. $A B$ delay and the age at which maximal OR performance was achieved were unrelated (Bell \& Fox, 1992). In the same study, Bell and Fox also found that frontal EEG power and coherence among frontal and other electrode sites were unrelated to OR performance. Matthews et al. (1996) examined $\mathrm{AB}$ and $\mathrm{OR}$ performance in full-term and healthy preterm infants. Only $A B$ performance was related to term birth status. OR performance changed with advancing age, but was not related to term birth status. Matthews et al. concluded that only AB is dependent upon memory, which is determined by postnatal environmental experience.

Baillargeon and associates have proposed that other cognitive processes account for perseveration on AB (Baillargeon, DeVos, \& Graber, 1989; Baillargeon \& Graber, 1988; Baillargeon, Graber, DeVos, \&Black, 1990), namely, limitations in infant problem solving. In these studies, a preferential looking paradigm was used in order to evaluate whether infants identify the correct reward location. Younger (5-month-old) and older (8-month-old) infants identified the reward location by longer looking at location $A$ after a 70-s delay (Baillargeon et al., 1989). Baillargeon proposed that the breakdown in processing is not a result of misidentification of the object location (i.e., not a mnemonic process), but of poor execution or generation of appropriate manual search strategies. Perseverative errors, then, were postulated to occur as a result of misapplication of a previously successful manual retrieval, in light of inadequate strategy generation (Baillargeon et $1 \mathrm{al} ., 1990$ ).

Baillargeon's hypothesis predicts that AB performance would vary as a function of the type of output response. In a test of this premise,'Hofstadter and Reznick (1996) used gaze direction and manual reaching as:the dependent measures for DR. Perseverative errors were more common in the manual condition than in the gaze condition, consistent with Bajflargeon's premise. Perseverative reaching was more likely on trials following incorrect responses; however, the number of perseverative gaze and manual responses did not differ following correct responses. Hofstadter and Rezzick (1996) concluded that reinforcement affected the likelihood of perseverative gaze and manual responses equally. However, these authors attributed the increased perseverative manual responding to a priming effect related to the proximity of the efferent connections from dorsolateral prefrontal cortex to the caudate nucleus.

Findings from a study by Dehaene and Changeux (1989) also support Baillargeon's account. A minimal neural network model with two levels was employed to simulate $A B$ performance. The first level consisted of a sensori- 
motor loop with modifiable synaptic weights, providing the output grasping capacity. The second level contained a memory layer and a rule-coding layer, which modulated the first level. When only level I was simulated, perseveration at location $\mathrm{A}$ resulted. When level II was included, correct AB performance was achieved. Through simple reinforcement, task learning was achieved by selection among rule repertoires. Interestingly, Baillargeon's dissociation between identification and manual strategy generation was simulated by postulating an intermediate stage of connectivity between levels I and $\mathrm{ll}$, where the connections from level $\mathrm{Il}$ were not fully available. In this network model, correct information about the cue was encoded but was unable to guide behavior. The authors concluded that the model was consistent with slower maturation of the efferent pathways from prefrontal cortex relative to the afferent pathways.

Baillargeon's premise has been criticized because the preferential looking paradigm may not invoke the same cognitive processes as the traditional $A B$ (Hofstadter \& Reznick, 1996). Others have speculated that the identification of event possibility may be more akin to recognition memory than working memory per se. Matthews et al. (1996), for example, found comparable AB performance in gaze and manual conditions. Furthermore, performance on a problem-solving, Means-end task where the infant reached for a cloth to displace an object did not improve with age. Perseverative Means-end errors also were not age-related. Matthews et al. concluded that the fundamental cognitive process that underlies $\mathrm{AB}$ performance is mnemonic, not strategic.

All of these investigations established the component cognitjue processes by inference, informally contrasting performance on $A B$ to tasks which share or differ in purported demands. However, the identification of the rudimentary cognitive processes also can be examined by utilizing a construct validity approach. In this approach, the statistical relations among performance on $\mathrm{AB}$ and other comparison tasks are examined with factor analysis. For the current study, other comparison tasks were chosen that shared the response format (i.e., manual reaching) but differed in the "rule" required for correct retrieval. If $\mathrm{AB}$ and other comparison task performance clusters, that is, loads on the same factor, then these tasks share underlying variability that may reffect like cognitive demands. The goals of this study were twofold: (a) to examine the developmental pattern of $A B$ performance in preschool children and (b) to investigate the pattern of shared variability of $A B$ and other comparison tasks.

\section{METHOD}

\section{Participants}

Ont hundred and seventeen children, aged 23 to 66 months $(M=40.42$ months, $S D=$ 11.75). participaled ( $n=62$ malc; $n=55$ female). Preschool children were recruited from local hirth announcements ant presethols. The majority of the sample $(n=110)$ were Cauca- sian. The average matemal education wias 17.1 years ( $S D=2.2$ ). All ctildren weighed more sian. The average matemal $2500 \mathrm{~g}$ at birth. Developmental milestones were achieved appropriately by maternal rethan

\section{Apparatus}

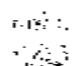

A gray, wooden testing board $(43.0$ by $20.0 \mathrm{~cm}$ ) with three shallow wells was used for most lasks. The center well was covered with a silyer disk and was not used. The two lateral wells were $21.5 \mathrm{~cm}$ apart, $2.5 \mathrm{~cm}$ in dianter, and less than $1 \mathrm{~cm}$ deep. Two ptastic beige inverted cups were used to cover the wells for alt lasks except for Color Reversal, where brue and yellow circular discs were employed.

\section{Measures and Procedure}

Generat. Children were tested individually in a quiet lesting room. The examiner and child sul at a them. All delayed response format tasks used the lesting board, but differed in how the reward-was hidden or response formal tasks used the lesting board, but differed in to obtain the reward. On all of these tasks, children were' instructed, "Find the \{reward.$"$ The right well was used for the rewiand on the first trial of all delayed response format tasks in order to teduce the early establishment of side preferences; as perseverative reaching has been demonstrated to be more oommon to the child's left side (Hofstadter \& Reznick, 1996). A different type of reward (i.e., small stickers, M \& M baking bits, colored Rice Krispies, raisins, Cheerios, and pennies) was used al the begining of each task and reintroduced when the child appeared to be losing interest in onder to maintain a high level of motization. During hiding, both wells were covered and re-covered simultaneously with the cups or discs to aroid auditory cueing of reward location. The isting board then was placed out of the child's sight under the table to prevent location cueing (e.g., leaning to the side of the reward) that has been demonstrated to improve performance (Diamond, 1985). A curtain was not used to occlude the testing board because, during pilot lesting, many preschoolers got out of their seat to peer behind the curtain. The examiner counted alout in an engaging voice for $10 \mathrm{~s}^{1}$ to maintain interest in the task and to distract the child from the lesting board. After the 10-s delay, the testing boadd was returned to the table and the child retrieved the reward. The child was allowed to keep or consume the reward only on correct trials.

All examiners were blinl to the bypotheses of the study. An error was scored when the child firmly touched or began to lift the cup or dise where the reward was not located. If the child subsequently reached toward of displaced the other cup or disc, the first response still was considered an error, consistent with scoring procedures used by Diamond (1985). A few

I A constant delay of $10 \mathrm{~s}$ was used for several reasons. Diamond (1985) has found that 'A constant delay of $10 \mathrm{~s}$ was used for several reasons. Diamond (1985) has found that
12-month-0ld infants exhibit AB error with a 10-s delay. However, Matthews et al. (1996) found that their term infants at 12 months were able to tolerale a 1.8 -s delay. Hofstadler and Reszrick (1996) used a 3-s delay for 7-, 9-, and 11-month-old children. Beil and Fox (1992) found two groups of iniants, a short delay eroup (the majority) who tolerated an average of atout $3 \mathrm{~s}$ and a long delay groug who tolerated a mean delay of $12 \mathrm{~s}$. Espy. Kaufmann, and Glisky (1999) used a 5 -s delay with 18 month olds to successfully discriminate performance Gisk pilot testing, it was observed that with longer delays, many children got up repeatedly from their seal andfor lost interest in the tasks quickly. Therefore, this delay was chosen to maximize the number of children in the age range who would be able to complete the task. A constanl delay was chosen, in order to maintain a consistent administration procedure across $\mathbf{A B}$ and comparison tasks in order to examine performance differences wilh age. 
children reached for both cups simultaneously. On the first occurrence of this behavior, these children did not receive the reward and were redirected to reach for a single cup only. The triat then was repeated. This behavior did not oceue on subsequent trials.

The tasks described in this study were administered as a part of a larger executive function hattery. They were adtainistered in the same order for all children: Se]f-Control 1, AB, Spatiai Reversal, Delayed Alternation, Color Reversal, Self-Control 2. Self-Control 1 was first in the battery in order to introduce the child to displacing an object to find a reward that was utilized in the other delayed response formal tusks. Other tasks from the larger battery that differed in response requirements (c.g., sustained vigilance, naming speed) were interspersed between each of the tasks described here. The specific lask procedures for $A B$ and the comparison lasks are described below.

AB. (Diamond, 1988 ). The child watched the examiner bide the reward under one of wo cups over the lateral wells of the testing board. The examiner removed the testing hoard from the table and distracted the child with counting. After $10 \mathrm{~s}$, the board was retumed. The child then displaced one cup to obtain the reward, if correct. After the child correctly netrieved the reward al the same location for two consecutive trials, the reward wias hidden in the other well. If the child displaced the cup with no reward, the reward remained at the same location until the child reached the two consecutive cortect criterion (Diamond et al, 1997) Consistent with other human ant animal studies using $\mathrm{AB}$, the reward was shifted from one lateral well to the other depending upon subject performance. For example, if a subject correctly responded on all trials, the onder of presentation would be AABBAABBAA, whereas presentation for another subject who erred on trials 3,4 , and 8 would be (subjects errors are highlighted) A.ABBBBAAAA Ten trials were administered, as Espy, Kaufmann, and Glisky (1999) found that $10 \mathrm{AB}$ trials were sufficient to elicit individual perfortance variability. Four dependent Yariables were calculated: number of correct responses (ABCORR), number of correct consecutive responses (ABCRUN), number of perseverative errors committed after the first conect two-trial set was achieved (ABPERR), and number of triats in the longest run of consecutive perseverative etrors (ABPRUN). On AB, not all enors were perseverative, as perseverative errors were counted only for trials that occumed after the child had correctly retrieved the reward consecutively for two trials. These measurcs were chosen in order to achieve measurement consistency across indisidual children and the differing delayed response format tasks.'

Self-controt. (SC; Lec, Vaughn, \& Kopp, 1983). This task was chosen to assess inhibition, instead of OR (Diamond, 19906 ), in onder to closely mimic the demand characteristics of $A B$. In SC, the child was shown the reward. The examiner used an animated tone to comment on reward desirability (c.g.. "These M M M's sure look good. I like green ones, do you? Yum yum." ). There were two trials. In $\mathrm{SC}$, the reward then was hiden under the cup on the lesting board (only a single wiell and cup were used). In SC2, the reward was a wrapped gift.

${ }^{2}$ Diamond (1985) used a variable trial, variable delay $A B$ procedtre where infants wiere administered the task repcatcdly. The length of the delay was reduced or increased depending on subject performance. Then, the number corsect on reversal and repeal trials was calculated For the purposes here. that is, to examine patterns of perfomance across $\mathrm{AB}$ and other delayed response formal tasks, the number of trials was fixed across subjects, maintaining consistent administration across subjects and tasks. Because individual subject perfornance deternined the number of reqersals in the fixed trial administration, more global measures (i.e., ABCORR, ABPERR) were considered to better eaplune individual differences in performance. If the number of correct reversal trials had been used as a dependent measure as the lasks were adininistered, the number of reversal trials antministered would be confounded with subject perfomance. These global measures also provided a more consistent metric aceoss the dirfering delayed response Eormal tasks. which was placed directly on the table. The child was instructed not to tonch the reward while the examiner completed another task. The examiner then backed up trom the table, tumed partially away from the child, and reviewed test sheets while sumeptiously monitoring the child. The latency to touch the reward on each trial was scored with a maximurn of $150 \mathrm{~s}$.

Delayed alternation, (DA; Goldman, Rosvold, Vest, \& Galkin, 1971) DA was included because of the presumed reliance on working memory (Goldman et al., 1991), as DA performance has beer linked to dorsolateral prefrental cortical function in animals (Diamond, 199); Goldman-Rakic, 1987a). The testing board was used. In DA, the reward was bidden out of the child's sight (i.e, with the lesting board under the table), which was unlike $\mathrm{AB}$, where the child obserwed the reward being placed in the well. After comect retricylt on a single DA trial, the examiner hid the reward in the altemate well. Like $\mathbf{A B}_{1}$ when the rewand was shifted. [rom one lateral well to the olher depended upous subject performance. To achieve the maximaI correct, the child must alternate retrieual from right to left wells on each successive trial. when the child distupted the alternation by searching on the same side, the examiner hid the reward at the same location until correct retrieval occurred. Based on pilot testing, 20 trials were administered to elicit sufficient performance variability. Three dependent measures were sconed: number correct (DACORR), number of consecutive correct trials in the longest run of altemations (DACRUN), and number of trials in the longest perseverative nun (DAPRUN). Because there were only two wells, all errors were perseverative, and thus the numbers of cortect and error responses were redundant.

Spatidl reversal, (SR; Kaufmann, Leckman, \& On, 1989). SR was presumed to depend on working memory to a degree by maintaining the response sel over a delay and on problem solving or concept formation because the child had to generate the rule (in this case, focalion) by which to correctly retrieve the teward. SR utilized the testing board, but unlike AB, the child did not observe hiding of the reward. Similarly to $\mathrm{AB}$ though, the child retrieved the reward until a criterion of conseculiue correct netrievals at the same location was met. Then, the reward was hidden in the other well. At which triak the reward was shifted between locations depended on the child's performance (i.e., when the criterion of consecutive comect trials was obtained). The criterion of four trials was used (instead of two trials in AB), as results from the pilot study (Kaukmann et al., 1989) reyealed that more trials within a set were necessary to establish the hiding rule when the child did not observe the hiding of the reward. There were 20 trials, as the 4 -trial relrieval criterion requited mote trials in onder to maintain a suffcient number of shifts between hiding locations. Three dependent measures were scored: number of correct responses (SRCORR), number of perseverative errors after the first corJecl sel (SRPERR), and number of consecutive trials in the longest perseverative run (SRPRUN).

Color reversal. (CR: Kaufmann et al., 1989). Like SR. CR wias postulated to measure working memory and problcm solying but $S R$ and $C R$ differed in the nature of the hiding rule. li SR, the rule utilized location; in CR, it was visual (color). Instead of using the cups to cover the wells, one blue and one yellow dise were used, where the colored dises moved between sides andomty across trials. As in DA and SR, the child did not observe the examiner hiding the reward in CR. When the child retrieved the reward from bencst the colored disc correctly for four consecutive irials, the reward then was hidden beneath the disc of the other colvr. Like SR, at which lial the reward was shiftod between locations depended on the child's performance (i.e., when the criterion of consecutive onrect trials was obtained). Twenty trials were administered. Three dependent measures were scored: number of correct responses (CRCORR), number of perseverative errors after the first correct set (CRPERR), and number of consecutive trials in the longest perseverative run (CRPRUN).

futerligence. The Peahody Picturc Yocabulary Test-Revised, Form M (PPVT-R; (Dunn \& Dunn, 1981 ) was administered to estimate intelitigence in children at or above 2 years of age. The resulting standard scone was the dependent measure. There were nine children under 2 years of age to withom the PPVT-R was not administered. Task performance on each measure for the entire sample is depicted in Table 1. 
TABLE 1

Sample Task Performance

\begin{tabular}{lcrcc}
\hline Measure & $N$ & $M$ & $S D$ & Range \\
\hline ABCORR (trials) & 116 & 8.20 & 1.60 & $3-10$ \\
ABCRUN (trials) & 116 & 5.78 & 2.75 & $2-10$ \\
ABPERR (trials) & 116 & 1.51 & 1.34 & $0-7$ \\
ABPRUN (trials) & 116 & 1.07 & 0.94 & $0-5$ \\
DACORR (trials) & 111 & 12.11 & 3.01 & $5-20$ \\
DACRUN (trials) & 111 & 4.52 & 3.21 & $0-17$ \\
DAPRUN (trials) & 111 & 2.18 & 1.23 & $1-9$ \\
SRCORR (trials) & 102 & 13.57 & 1.77 & $5-16$ \\
SRPERR (triats) & 98 & 4.81 & 1.75 & $0-9$ \\
SRPRUN (trials) & 102 & 2.09 & 1.04 & $1-6$ \\
CRCORR (trials) & 98 & 12.68 & 1.91 & $8-16$ \\
CRPERR (trials) & 80 & 4.45 & 1.84 & $1-11$ \\
CRPRUN (trials) & 98 & 3.70 & 1.53 & $2-9$ \\
SCONT1 (seconds) & 114 & 125.57 & 5.08 & $0-150$ \\
SCONT2 (seconds) & 119 & 119.47 & 53.90 & $1-150$ \\
PPVTR & 79 & 110.57 & 10.78 & $86-140$ \\
\hline
\end{tabular}

Note. The number of subjects is less for CRPERR and SRPERR because perseverative errors are calculated after the first correct set is achieved. There wiere 4 subjects for SR and 18 subjects for $C R$ who never achieved a correct four-trial sel.

\section{Design and Analysis}

A linear regression design wias used to examine age-related performance on each of the dependent measures. It was anticipated that task performance would improve with age, that is, more correct and fewer perseverative error responses. Individual differences in task performanee due to sex and intelligence atso were examined. For these analyses, sex was dummy coded $(1=$ male, $0=$ female $)$ and then entered in the repression equation. Where sex signifcantly predicted task perfotmance, it was reentered in the regression equation with age and the interaction of sex and age, in order to examine wihether the age effect differed by sex. The same analytic strategy was used in order to cxamine the effect of intelligence.

Exploratory factor analysis was conducled in onder to assess AB measurement characteristics. First, principal component analysis was conducled in order to determine the number of factors to extract. Those factors with Eigen values greater than 1.00 (Kaiser, 1960) wiere retained. The Scree plot (Cattell, 1966) also was examined to confirm exiraction (Velicer, Pea cock, \& Jackson, 1982). Then, a sccond principal components analysis was performed where the number of factors to extract was specifted, using varimax rolation for ease of interpretation. Yarimax rotation was chosen for two reasons. First, varimax rotation disperses variability across factors (Gorsuch, 1983). Because it has been proposed that AB performance is determined by more than one cognitive component (Diamond \& Goldman-Rakic, 1989), methods that are more likely to yicld a unitary factor (i.e., quartimax) were not appropriate. Furthermore, the hypothesized shared variability among $A B$ and the comparison tasks were postulated to he relative] y distinct; therefore, an orthogonal rotation was considered appropriate (Comrey. 1978). ${ }^{3}$ In order to detemine the underlying measurement characteristics, all factor loadings

The assumption of factor independence was investigated subsequently by examining the factor pattern intercortclations using an oblique, Harris-Kaiser rotation (Gorsuch, 1983). In order to assess the adequacy of the assumption of factor independence, the data were reana-
TABLE 2

The Relasion of Age to Task Performance $+1$

\begin{tabular}{|c|c|c|c|c|c|}
\hline Measure & $M$ & Estimated age effecl & Standard error. & 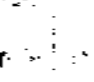 & $\begin{array}{l}\text { Yariance } \\
\text { explained }\end{array}$ \\
\hline ABCORR & 116 & $0.66 * * * *$ & 0.14 & -7 & 16.28 \\
\hline ABCRUN & 116 & $1.28^{* * * *}$ & 0.24 & & 20.66 \\
\hline ABPERR & 116 & $-0.67^{* * * * *}$ & 0.11 & & 23.62 \\
\hline ABPRUN & 116 & $-0.36 * * * *$ & 0.08 & . & 14.05 \\
\hline DACORR & 111 & $2.44 * * * *$ & 0.34 & & 32.26 \\
\hline DACRUN & 111 & $1.80^{* * * *}$ & 0.27 & & 29.55 \\
\hline DAPRUN & 111 & $-0.52 * * * *$ & 0.11 & $\therefore$ & 16.34 \\
\hline SRCORR & 102 & 0.21 & 0.19 & & 1.21 \\
\hline SRPERR & 98 & $-0.32^{\perp}$ & 0.19 & 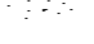 & 2.90 \\
\hline SRPRUN & 102 & $-0.28^{* *}$ & 0.11 & & 6.98 \\
\hline CRCORR & 98 & $0.45^{*}$ & 0.21 & & 4.56 \\
\hline CRPERR & 80 & -0.23 & 0.23 & & 1.34 \\
\hline CRPRUN & 98 & $-0.38 *$ & 0.17 & & 5.07 \\
\hline SCONT1 & 114 & $23.91 * * * *$ & 4.35 & & 21.27 \\
\hline SCONT2 & 106 & $23.52 * * * *$ & 4.99 & & 17.62 \\
\hline
\end{tabular}

Note. The number of subjects is less for CRPERR and SRPERR because perseverative erors are calculated from first set achieved.

$* * * * p<.000 \mathrm{l},{ }^{* *} p<.0 \mathrm{I}, *_{p}<.05_{+} p<.10$.

greater than \pm 0.50 were used for interpretation. All analyses were contucted with SAS Version 6.12 .

\section{RESULTS}

Consistent with prediction, age significantly predicted ABCORR ( $F(1$, $114)=22.17, p<.0001), \mathrm{ABCRUN}(F(1,114)=29.68, p<.0001)$, ABPERR $(F(1,114)=35.25, p<.0001)$, and ABPRUN $(F(1,114)=18.64$, $p<.0001)$. The relation of age to performance on $\mathrm{AB}$ and the comparison tasks also is presented in Table 2. Age accounted for large portions of the variability in $A B$ performance, ranging from 14 to $23 \%$. The estimated effect of age on ABCORR was 0.66 trials, indicating that a given child, on average, would be expected to score an additional 0.66 trials per age year (depicted in Fig. 1). ABCRUN performance increased an average of 1.28 trials per year, whereas age was related to a decrease of 0.67 ABPERR trials per year and of 0.36 ABPRUN trials per year.

Among the comparison tasks, age significantly predicted DACORR, ( $F(1$,

Iyzed using Harris-Kaiser oblique rotation. After rotation, the factor pattern was idenlical ard the factor loadings were of similar magnitude. The four factors axes were not highly correlated $\left(r_{12}=-0.02 r_{13}=0.32, r_{14}=-0.05, r_{23}=-0.18, r_{34}=.13, r_{34}=0.04\right)$. The highest corclation was between faclor axes 1 and 3 , which was not surprising given $A B$ performance incasures loaded on both of these factors. Therefore, the assumption of independence of the latent factors in orthogonal rotation was considered parsimonious and appropriate. 


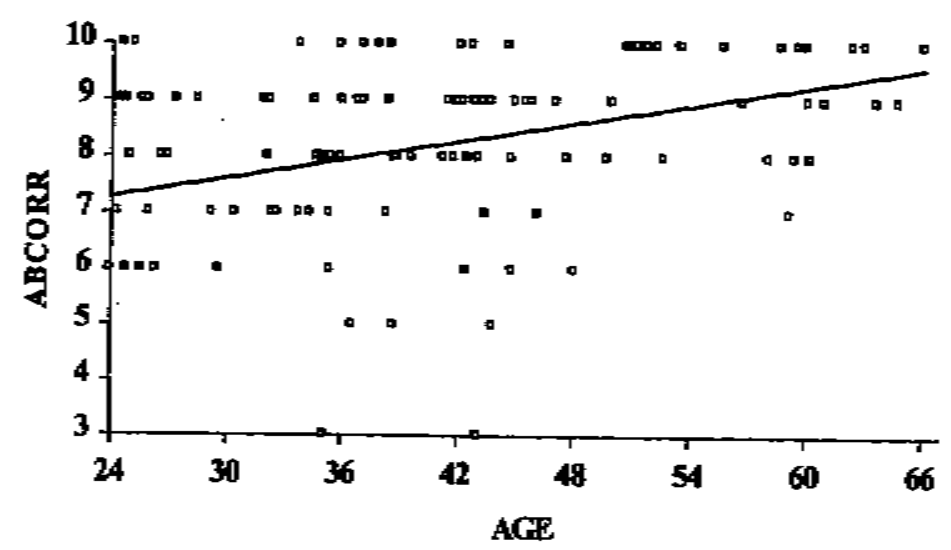

Note. Age is in months

FIG. 1. A-not-B total number correct by age.

$109)=51.91, p<.0001)$, DACRUN $(F(1,109)=45.71, p<.0001)$, DA PRUN $(F(1,109)=21.30, p<.0001)$, SRPRUN $(F(1,100)=7.04, p<$ $.01)$, CRCORR $(F(1,96)=4.58, p<.05)$, CRPRUN $(F(1,96)=5.13$ $p<.03), \operatorname{SC1}(F(1,114)=30.25, p<.0001)$, and SC2 $(F(1,104)=22.24$, $p<.0001)$ performance. Age accounted for the greatest percentage of variability in the DA measures, that is, between 16 and $36 \%$. Figures 2,3 , and 4 present the total number correct performance indices for each task by age. The estimated age effect ranged from 2.44 trials per year for DACORR to 0.21 for SRCORR.

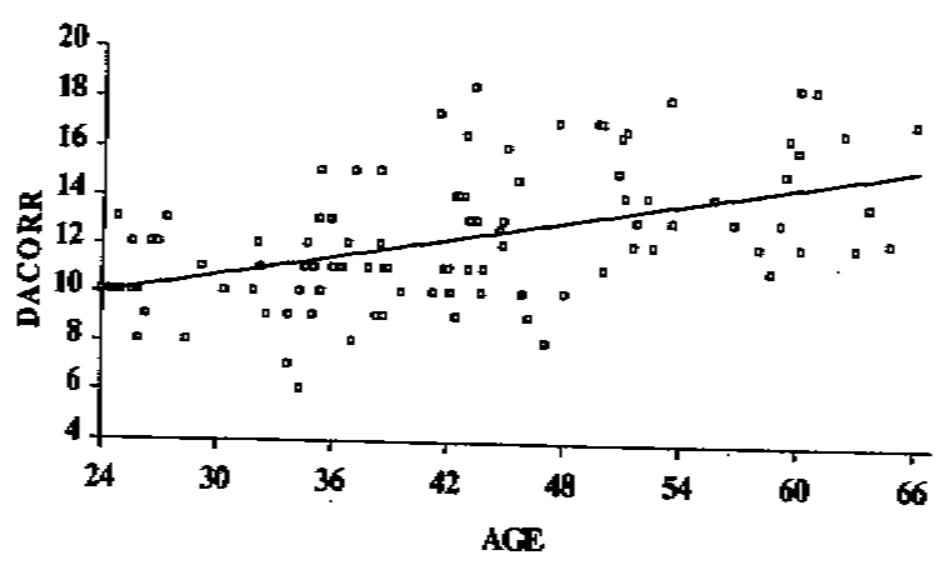

Note. Age is in months

FIG. 2. Delayed alternation total number correct by age.

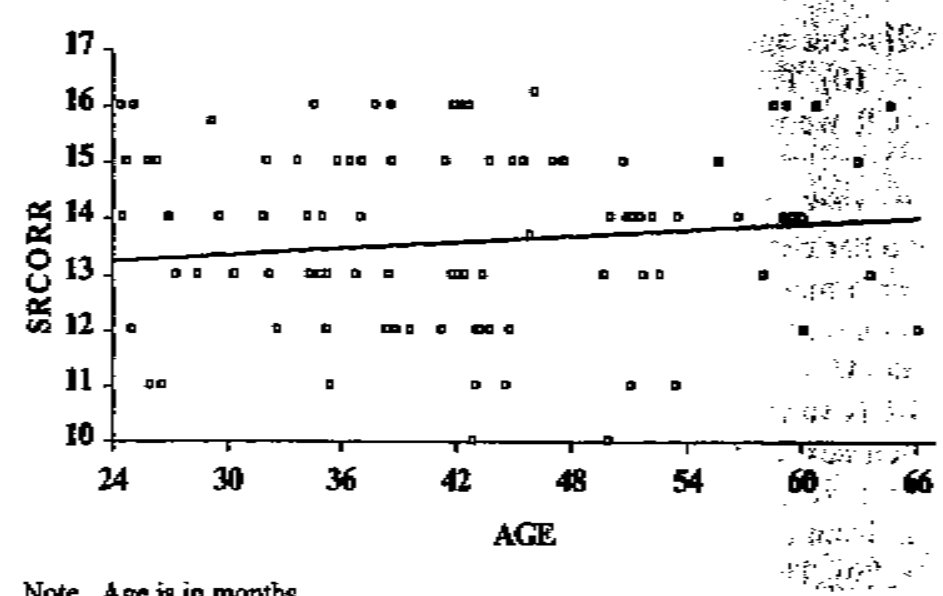

Note. Age is in months

FIG. 3. Spatial reversal total number correct by age.

\section{Individual Differences in Task Performance}

in:

There were children who were noncompliant or unable to complete the tasks ( $n=1, \mathrm{AB} ; n=6, \mathrm{DA} ; n=15, \mathrm{SR} ; n=19, \mathrm{CR}$; and $n=8, \mathrm{SC}$ ). Three children inadvertently were not administered SC1 and SC2. Thirtyfive children did not complete the PPVT-R due to fatigue or were not administered the task due to examiner error. Age significantly predicted whether a child was able to complete the DA, SR, and CR tasks (DA, $F(1,115)=$ $8.59, p<.001$; SR, $F(1,115)=13.40, p<.001 ; \mathrm{CR}, F(1,115)=40.89$,

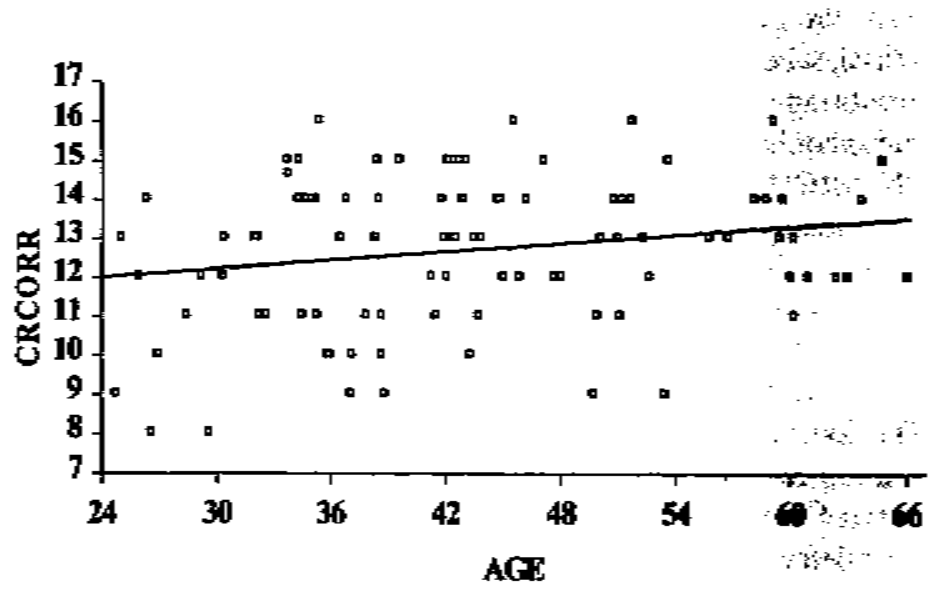

Note. Age is in manths

FIG. 4. Cotor reversal total number correci by age 
$p<.0001)$, but age was not related to the completion of SC2 $(F(1,115)=$ $2.44, p>.10$ ). The majority of children who were unable to complete DA, $\mathrm{SR}$, and $\mathrm{CR}$ were under 26 months of age $(n=4, \mathrm{DA} ; n=10$, SR; $n=$ $15, \mathrm{CR})$.

Sex was unrelated to ABCORR, ABPERR, ABPRUN, and all measures from the other comparison tasks. Sex, however, significantly predicted $A B-$ CRUN performance $(F(1,114)=3.98, p<.05)$. Females outscored males by an average of one additional ABCRUN trial (Female $M=6.31, S D=$ 3.01; Male $M=5.31, S D=2.43$ ). To examine whether the effect of age on ABCRUN varied with respect to sex, the sex by age interaction was examined. When sex, age, and the respective interaction were entered into the regression model, neither the sex main effect nor the sex by age interactive were significant (Sex, $F(1,112)=0.14, p>.70$; Sex X Age, $F(1,112)=$ $1.10, p>.29$ ). These results indicate that sex did not affect the development of ABCRUN skills. PPVT-R intellectual ability was unrelated to performance on all $\mathrm{AB}$ and comparison task measures (all $p^{*}>.10$ ).

\section{Task Measurement Characteristics}

Because exploratory factor analytic results are somewhat sample-dependent (Gorsuch, 1983), three hierarchical criteria were used to guide variable selection. Because higher subject-to-variable ratios yield more stable factor patterns (Comrey, 1978), single variables from among the correct and the perseverative error indices were included for analysis. Univariate task correlations also were analyzed in order to eliminate highly redundant variables (Gorsuch, 1983). ABCORR and ABCRUN were highly correlated, as were DACORR and DACRUN (all $r$ 's $>.80$ ). ABCRUN and DACRUN were retained for the purposes of analysis because, on the basis of face validity, these variables best reflected consistent reward retrieval. Finally, variables that were not age-sensitive were eliminated. On the basis of these criteria, 10 measures were retained for analysis: ABCRUN, ABPRUN, DACRUN, DAPRUN, SRCORR, SRPRUN, CRCORR, CRPRUN, SC1 and SC2. There were 82 subjects $(70 \%)$ who did not have any missing data across the 10 measures that were included in these analyses.

In the principal components analysis, four factors had Eigen values that exceeded 1.00 (Factor $\mathrm{I}=2.58$, Factor $2=1.78$, Factor $3=1.47$, and Factor $4=1.12$ ). The Scree plot also turned significantly after the fourth factor. The four factors accounted cumulatively for $69.48 \%$ of the variance, with the first through fourth factors each accounting for $25.76,17.80,14.7$, and $11.20 \%$ of the variance, respectively. All communalities exceeded 0.40 , indicating adequate measurement reliability (Gorsuch, 1983). The rotated factor loadings are depicted in Table 3 (those less than 0.50 were omitted).

Consistent with prediction, there was shared variability among $A B$ and comparison tasks. The first factor, which accounted for the greatest per-
TABLE 3

istor

Rolated Factor Loadings of AB and Comparison Tastos

\begin{tabular}{|c|c|c|c|c|}
\hline & \multicolumn{4}{|c|}{$\therefore \quad \therefore \quad \therefore$} \\
\hline & 1 & 2 & 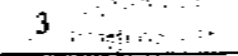 & 4 \\
\hline ABCRUN & 0.60 & & $0.54 \cdots$ & \\
\hline ABPRUN & -0.51 & & -0.65 & \\
\hline DACRUN & 0.79 & & $\therefore \div \quad \therefore$ & \\
\hline DAPRUN & -0.79 & & $\theta_{1}$ & \\
\hline SRCORR & & & $=1$ & -0.86 \\
\hline SRPRUN & & & $\therefore \because \quad \therefore$ & 0.89 \\
\hline CRCORR & & 0.87 & is: & \\
\hline CRPRUN & & -0.85 & $y_{2}=-1$ & \\
\hline SCONTl & & & 0.56 & \\
\hline SCONT2 & & & 0.77 & \\
\hline
\end{tabular}

Note. Varimax totation was used.

formance variability, comprised ABCRUN, ABPRUN, DACRUN, and DAPRUN. On this factor, the indices of correct performance were positive in sign, whereas the respective error indices were negative $\mathrm{A} B$ also loaded with SC1 and SC2 tasks on Factor 3. The factor loadings of ABCRUN and the SC inhibition latencies were positive in sign, whereas ABPRUN was negative. $C R$ and $S R$ task indices were unrelated to $A B$ performance and loaded respectively on Factors 2 and 4.

\section{DISCUSSION}

$A B$ performance steadily improved in preschool children between 23 and 66 months of age. Older preschool children retrieved the reward on more trials and made fewer perseverative errors on $A B$ than did younger children. Therefore, AB was sensitive to age-related differences beyond the late infancy age range, which has been more commonly studied (Diamond, 1985; Piaget, 1954; Wellman et al., 1986). It is likely that usisg more than one reversal trial, as Diamond (1985) suggested, captured age-related differences in AB performance in preschool children. These results lend support to Diamond's assertion that $A B$ is sensitive in older children, provided that a longer delay between hiding and retrieval is used. In this study, a standard delay of $10 \mathrm{~s}$ was used across children and age. This delay is significantly longer than what has been used in other studies where the delay increased incrementally and individually (ranging from a 1.8- to a 10.0-s delay at 12 months of age). A standard delay was chosen in this study to maintain a consistent administration procedure actoss $\mathrm{AB}$ and the comparison tasks in order to examine performance differences across age. Several researchers have found relatively large individual differences in the delay necessary to elicit the $A B$ error (Bell \& Fox, 1992; Diamond, 1985). In this study, perseverative re- 
sponding may not have been maximal, in that for some preschool children, a I0-s delay may not have been sufficient to elicit AB errors. In fact, many children older than 5 years of age achieved perfect AB performance. It is likely that using a longer delay with the older children would have elicited more AB errors. Despite the constant delay, age accounted for a large percentage of the variability in AB performance in this study.

Performance on most of the comparison tasks also was related to age. Age accounted for the most variability in DA performance and age effects were observed on all DA indices. However, performance on CR and SR was not related as consistently to age as AB, DA, and SC. However, some of the youngest children were not able to complete the SR or CR tasks. Because the number of children that could not complete these tasks was comparable, it does not appear that these difficulties were due to age-related color skills. Because children were not specifically instructed that the reward was coupled with disc color on $C R$, the comparable number of children who were able to complete the SR and CR tasks suggests that it was the task format, not the retrieval rule, that was related to task failure. Because of the longer criterion necessary to demonstrate encoding of the retrieval rule on these tasks where the reward hiding was not observed, CR and SR may be more difficult for the younger subjects. These measurement issues reduced task variability in the youngest children and may have reduced the power to detect age effects on these tasks. Because some younger subjects could not complete these tasks, their data were not included in the factor analysis and, therefore, did not affect the observed loading pattern.

There were few individual differences in $\mathrm{AB}$ and comparison task performance. Sex, for the most part, did not predict task performance. However, females correctly searched consecutively by an average of one additional trial on AB compared to males. This difference is consistent with findings from other investigations using $A B$ in infants, where females tolerated longer delays and searched for the hidden reward at an earlier age than males (Diamond, 1985; Diamond \& Doar, 1989). Neither this study nor those by Diamond have found that sex affected the age-related rate of performance change. In light of the number of variables, and therefore statistical comparisons, the sex difference on the single AB measure found in this study may be spurious.

Performance on AB and the comparison tasks also was not related to intelligence. This distinction is supported by other studies of executive function development in school-aged children (Levin et al., 1991; Welsh, Pennington, \& Groisser, 1991). Interestingly, one clinical hallmark of frontal lobe dysfunction is relative preservation of intellectual abilities, in light of gross deficits in judgement, planning, working memory, and inhibition (Eslinger \& Damasio, 1985). The observation of this pattern in normal preschool children suggests that the distinction of executive from intellectual skills may be applicable across the life span.
More generally, Diamond (1990a) has related AB perforasocestoprefrontal cortical maturity in infancy. Clearly, there are importantectinges in the dorsolateral prefrontal cortex that occur later in the preschool years; mainly in synaptic reorganization (Huttenlocher, 1979; Thatcher, 1997), Whether the age-related changes in $A B$ and comparison task performance observed in this study reflect the continued maturation of the prefrontal cortex during the preschool period is an important question. Maturational changes in behavior do not necessarily map onto the development of brain structure and function with one-to-one correspondence (Diamond, 1991). Concurrent measures of brain function and $A B$ performance in preschool children is necessary in order to examine this issue directly.

DA performance also has been linked to the function of the dorsolateral prefrontal cortex in animals (Goldman et al., 1971), but this task has not been used often in studies with humans. The findings from this study indicate that DA performance improves reliably with age and may be a useful tool with which to investigate cognition in preschool children. DA bas been used in older children who sustained injury to the prefrontal cortex secondary to closed head injury (Levin et al., 1994). In that study, DA performance was not related to frontal lobe lesion size on MRI in school-aged children. However, Levin et al. concluded that DA was not valid in this age range because many head-injured and control children reported using a more complex retrieval rule than simple alternation and therefore committed many unnecessary errors.

The results from the factor analysis indicated that variability in $\mathrm{AB}$ performance was shared across two factors; loading with DA and SC performance, respectively. $\mathrm{AB}$ performance, then, may be related to two underlying cognitive components, at least when considered in the context of these comparison tasks. Interestingly, AB and the delayed response paradigm tasks, DA, SR, and $C R$, measured unique aspects of cognition, despite shared administration procedures (i.e., manual retrieval of a hidden reward) and proposed reliance on working memory. Because a unitary factor did not emerge, working memory, as a monolithic construct, may not be the major determinant of performance on the tasks included here.

The first factor, accounting for the greatest proportion of the variance, included both $A B$ and DA indices. Although $A B, D A$, and $S R$ share a spatial location component, conceptually, DA may have the greatest demand on working memory among these tasks. Correct performance on any given trial is almost entirely dependent on performance on the previous trial. No salient cues are present at the time of retrieval to guide performance, as the cups are indistinguishable. The side of hiding changed after each correct trial, requiring "on-line" processing. SR, on the other hand, may be more ralebased and, thereby, less working memory dependent. In SR, the child had to "discover" the hiding rule, in this case, a given location. The rule was the same across trials until the particular criterion was reached, perhaps acti- 
vating working memory to a lesser extent than $D A$ or $A B$. $A B$ also loaded on Factor 3 with SC indices. Successful AB performance also may depend on inhibition of the previously rewarded response. SC was adapted from developmental paradigms, originally developed in the context of compliance. SC was postulated to assess children's ability to wait or to inhibit reaching in response to an internal desire for reward (Welsh \& Pennington, 1988). Taken together, these findings suggest that the cognitive components of $A B$ performance include both working memory and response inhibition, consistent with Diamond and Goldman-Rakic (1989).

The common loading of $A B$ and $D A$, however, may be related to other cognitive domains, such as attention. Mirsky, Anthony, Duncan, Ahearn, and Kellam (1991) have proposed a four-factor model of attention, of which the focus/execute and switch factors are germane. The shared variability in $\mathrm{AB}$ and DA may require both spatial encoding and flexible switching among alternative reward locations. According to this view, the critical element is not holding information "on-line," but rather, flexible shifting among response alternatives. Focus/execute (Mirsky et al., 1991) and inhibition (Diamond \& Goldman-Rakic, 1989) both include cognitive processes requiring response restraint. This two component view of $A B$ performance from the perspective of attention also is consistent with Posner and Peterson's (1990) neural substrate model of attention. In their model, attention processes are distributed widely throughout the brain, but are composed of two subnetworks, the anterior and posterior. The anterior subnetwork, including the dorsolateral prefrontal and orbital cortex and limbic and other subcortical structures, is hypothesized to detect signals. It utilizes both internal data from memory storage in the hippocampus and current sensory input from the parietal cortex, in order to process information across time. It is difficult to determine whether the shared variability among $\mathrm{AB}, \mathrm{DA}$, and $\mathrm{SC}$ is attentionbased or mnemonic.

SR and CR performance did not load with AB performance despite like administration, suggesting that these tasks were less dependent on working memory than originally proposed. These tasks also were postulated to depend, at least in part, on problem-solving skills in preschool children, similarly to the Wisconsin Card Sorting Test (Heaton, 1981). In both SR and $\mathrm{CR}$, the child determined the retrieval rule and maintained it to guide performance until the contingency changed after the criterion was met. The separate loading of $S R$ and $C R$ may reflect the salience of the rule distinction in young children. CR and SR also are similar to the Object Reversal and Discrimination tasks used in animal neuroscience investigations, where the monkey retrieves a reward according to a rule until the performance criterion is reached, when the reward is changed (Clark \& Goldman-Rakic, 1989; Mishkin, 1964). Performance on these discrimination tasks has been linked to orbitofrontal cortex (Goldman, Crawford, Stokes, Galkin, \& Rosvold, 1974: Mishkin. 1964). Interestingly, the problem solving required for these tasks is similar to the "strategy generation" processes in $\triangle \mathrm{A}$ i proposed by Baillargeon et al. (1990). Given the proximity and interconnections'among the dorsolateral prefrontal and obital frontal areas and the subcortex, it would not be surprising that these cognitive functions may be complementary.

Roberts and Pennington (1996) have proposed that working memory resources, task demands, and prepotent response inhibition competitively interact. Therefore, if the prepotent response is particularly strong or the working memory demand high, strong perseverative responding occurs when cognitive processes breakdown. AB is considered relatively balanced in terms of working memory demands and prepotency strength. Other "frontal" tasks are more heavily loaded in one direction. The Wisconsin Card Sorting Test (Heaton, 1981), and perhaps SR and CR, may have less of a built-in response bias; therefore, working memory would be more heavily utilized in order to achieve correct performance. Other tasks, such as the Stroop (Golden, 1978) and perhaps SC, have a stronger prepotent response bias where less working memory activation is required. The findings from the present study are not entirely consistent with this model. If working memory and inhibition of the response prepotency interact, a single, general factor should emerge with the more working memory-dependent tasks, $\mathrm{CR}$ and $\mathrm{SR}$, positive in sign and the more inhibition-related task, like $\mathrm{SC}$, negative in sign. $\mathrm{AB}$ and perhaps DA would load positively or negatively, perhaps with the correct indices loading positively and the error indices negatively. The results from the present study indicate that rule-based problem solving on $S R$ and CR is separable from the cognitive processes required on $A B, D A$, and SC.

Correspondingly, these findings suggest that perseveration, which traditionally has been considered a unitary phenomenon related to frontal lobe dysfunction, especially in clinical populations, differs depending on task requirements. In this study, perseveration indices were inversely related to correct performance as expected, but loaded according to task demand, rather than as a common factor. These results are consistent with those of Hofstadter and Reznick (1996), who found that perseverative performance differed for reaching and gaze responses. In the present study; all perseverative responses were motoric, yet the differences in cognitive demands among tasks yielded independent measures of perseveration. These findings are consistent with Goldman-Rakic's (1987b) conceptualization of material-specific working memory which, when dysfunctional, produces material-specific perseverative errors.

These findings must be interpreted in light of the limitations of factor analysis. Labeling a factor of shared variability among tasks is not comparable to identifying component cognitive constructs (Pennington, 1996). It is, however, one approach that complements the existing literature provided by other developmental neuropsychological investigations. Underlying cognitive phenomena also can be studied in clinical populations with dissociable 
neuropsychological profiles and/or underlying brain abnormalities. Clinical neuropsychological approaches are just beginning to be conducted in preschool children. For example, AB performance differed in prenatally cocaine-exposed toddlers compared to nonexposed controls (Espy et al., 1999). AB, SR, and CR also have been used in older, but cognitive-limited developmentally disabled populations, such as children with autism and mental retardation (Kaufmann et al., 1989; McEvoy, Rogers, \& Pennington, 1993). More generally, these findings suggest that tasks adapted from neuroscience paradigms offer a rich methodology by which to examine brainbehavior links in preschool children.

\section{REFERENCES}

Baillargeon, R., DeVos, J., \& Graber, M. 1989. Location memory in 8-month-old infants in a nonsearch AB task: Further evidence. Cognitive Development, 4, 345-367.

Baillargeon, R., \& Graber, M. 1988. Evidence of location memory in 8-month-old infants in a nonsearch AB task. Developmental Psychology, 24, 502-511.

Baillargeon, R, Graber, M., DeVos, J., \& Black, J. 1990. Why do young infants fail to search for hidden objects? Cognition, 36, 255-284.

Bell, M. A., \& Fox, N. A. 1992. The relations between frontal brain electrical activity and cognitive developtnent during infancy. Child Development, 63, 1142-1163.

Cattell, R. B. 1966. The scree test for the number of factors. Multivariate Behavioral Research, $1,245-276$.

Chugani, H. T., \& Phelps, M. E. 1990. Imaging humas brain development with positron emission tomography. Jowrial of Nuctear Medicine, 32, 23-25.

Clark, A. S. \& Goldman-Rakic, P. S. 1989. Gonadal hormones influence the emergence of cortical function in non-human primates. Behtovioral Neuroscience, 103, 1287-1295.

Comrey, A. J. 1978. Common methodological problems in factor analytic studies. Joumat of Consulting and Clinical Psychology, 46, 648-659.

Dehaene, S., \& Changeux, J. 1989. A simple model of prefrontal cortex function in delayedresponse tasks. Journal of Cognitive Neuroscience, 1, 244-261.

Diamond, A. 1985. Development of the ability to use recall to guide action, as indicated by infants' performance on AB. Child Development, 56, 868-883.

Diamond, A. 1988. The abilities and neural mechasisms underlying AB performance. Child Developments, 59, 523-527.

Diamond, A. 1990a. The development and neural bases of memory functions as indexed by AB and delayed response tasks in human infants and infant monkeys. Antrats of the New York Academy of Sciences, 608, 267-317.

Diamond; A. $1990 \mathrm{~b}$. Developmental time course in human infants and infant monkeys, and the neural bases of, inhibitory control in reaching. Anrats of the New York Academy of Sciences, 608, 637-676.

Diamend, A. 1991. Guidelines for the study of brain-behavior relationships during development. In H. S. Levin, H. M. Eisenberg, \& A. L. Benton, (Eds.), Fronial lobe function and d) sfunction. New York: Oxford Univ. Press. Pp. 339-380.

Diamond, A., \& Doar, B. 1989. The performance of human infants on a measure of frontal cortex function, the delayed response task. Developmental Psychobiology, 22, 271-294.

Diamond, A., \& Guldman-Rakic, P. S. 1986. Comparative development of human infants and infant rhesus monkeys of cognitive functions that depend on the
Neuropsychological Abstracts, 12,274 .

Diamond, A., \& Goldman-Rakic, P. S. 1989. Comparison of human infants wad thesus monkeys on Piaget's AB task: Evidence for dependence on dorsolateral preffrontol cortex. Experimental Brain Research. 74, 24-40.

Diamond, A., Prevor, M. B., Callendar, G., \& Druin, D. P. 1997 : Prefrontal corlex cognitive deficits in children treated early and continuously for PKU. Monographs of the Saciety for Research in Child Development, 62, (4, Serial No. 252).

Dunn, L. M.. \& Dunn, L. M. 1981. Peabady Picture Vocabulary Test-Revised (From M). Circke Pines, MN: Am. Guidance Service.

Eslinger, P. J., \& Damasio, A. R. 1985. Severe disturbance of higher cognition after bilateral frontal lobe abtation: Patient EVR. Neurotogy, 35, 1731-1741.

Espy, K. A., Kaufmann, P. M., \& Gisky, M. L. 1999. Neuropsychologic function in toddlers exposed to cocaine in utero: A preliminary study. Developmental Newropsychology, 15, $447-460$.

Fox, N. A. \& Bell, M. A. 1990. Electrophysiological indices of froatal tobe development: Relations to cognitive and affective behavior in human infants over the first year of life. Annals of New York Academy of Science, 601, 677-704.

Fuster, J. M. 1985. The prefrontal cortex and temporal integration. In A. P.E. G. Jones (Ed.). Cerebral cortex, (Vol. 4. New York; Plenum. Pp. 151-177.)

Golden, C. J. 1978. Stroop color word test. Chicago: Stoelting.

Goldman, P. S., Crawford, H. T., Stokes, L. P., Galkin, T. W., \& Rosvold, H. E. 1974. Sexdependent beharioral effects of cerebral cortical lesions in the developing thesus monkey. Science, 186, 540-542.

Goldman, P. S., Roswold, H. E. Vest, B., \& Galkin, T. W. 197I. Analygis of the delayedaltemation deficit produced by dorsolateral prefrontat lesions in the rhesus monkey. Journal of Comparative and Physiological Psychology, 77, 212-220.

Goldman-Rakic, P.S. 1987a. Circuitry of primate prefrontal cortex and regulation of behavior by representational knowledge. In F. Plum \& V. Mountcaste (Eds.), Handbook of physiology, (Vol. 5). Bethesda, MD: Am. Physiol. Soc. Pp. 373-417.

Goldman-Rakic, P. S. $1987 \mathrm{~b}$. Development of cortical circuitry and cogonitive function, Child Development, 58, 601-622.

Gorsuch, R. L. 1983. Factor analysis, 2nd ed. Hillsdale, NJ: Erlbaum.

Heaton, R. K. 1981. Wisconsin Card Sorting Test mantuat. Odessa, FL: Psychological Assessment Resoutces.

Hofstadter, M., \& Rezrik, J. S. 1996. Response modality affects humar infant delayedresponse performance. Child Development, 67, 646-658.

Hutlenlocher, P. R. 1979. Synaptic density in human frostal cortex-Developmental change and effects of aging. Brain Research, 163, 195-205.

Huttenlocker, P. R., \& Dabhotkar, A. S. 1997. Developmental anatomy of prefrontal cortex. In N. A. Krasnegor, G. R. Lyon, \& P. S. Goldman-Rakic (Eds.), Development of the prefrontat cortex: Evolution, neurobiology, and behavior. Baltimote, MD: Brookes. Pp. 69-83.

Kaiser, H. F. 1960 . Application of electronic computers to factor aralysis. Educational and Psychological Measurement, 20, 141-151.

Kautmann, P. M., Leckman, J. M.. \& Ont, S. I. 1989. Delayed response performance in males with Fragile-X. Joumal of Ctinjcal and Experimental Neuropsychology, 12,69.

Kinney, H. C., Brody, B. A., Kloman, A. S., \& Gilles, F. H. 1988. Sequence of central nervous 
system myelination in human infancy. Joumat of Neuropathology and Experimental Neurology, 47, 217-234.

Lee, M., Vaughn, B. E., \& Kopp, C. B. 1983. The role of self-control in young children's performance on a delayed response memory for location lask. Developmental Psychology.
$19,40-44$.

Levin, H. S., Culhane, K. A., Fletcher, J. M., Mendelsohn, D. B., Lilly, M. A. Harward, H., Chapman, S. B., Bruce, D. A., Bertolino-Kusnerik, L., \& Eisenberg, H. M. 1994. Dissociation between delayed altemation and memory afler pediatric head injury: Relationship to MRI findings. Journal of Child Neurology, 9, $8 \mathrm{I}-89$.

Levin, H. S., Culhane, K. A., Hartmann, J., Evankovich, K., Mattson, A. J., Harward, H. Ringhoiz, G., Ewing-Cobbs, L., \& Fletcher, J. M. I99I. Developmental changes in performance on tests of purported frontal lobe functioning. Developmental Neuropsychology,
$7,377-395$.

Matthews, A., Ellis, A. E., \& Nelson, C. A. 1996. Development of preterm and full-term infant ability on $\mathrm{AB}$, recall memory, transparent barier detour, and means-end tasks. Child Development, 67, 2658-2676.

McEvoy, R. E., Rogers, S. J., \& Penninglon, B. F. 1993. Executive function and social communicative deficits in young auljstic children. Jowrnal of Child Psychology and Psychiatry. 34, 563-578.

Mirsky, A. F., Anthony, B. J., Duncan, C. C., Ahearn, M. B., \& Kellan, S. G. 1991. Analysis of the elements of attention: A neuropsychological approach. Neuropsychology Review, 2, $109-145$.

Mishkin, M. 1964. Perseyeration of central sets after frontal lobe lesion in monkeys. In J. M. Warren \& K. Aker (Eds.), The frontal granular cortex and behovior. New York: McGraw-Hil].

Pennington, B. F. 1996. Dimensions of executive functions in nomal and abnormal development. In N. A. Krasnegor, G. R. Lyon, \& P. S. Goldman-Rakic (Eds.), Development of the prefrontal cortex: Evolution, neurobiology, and behtavior. Baltimore, MD: Brookes.

Piaget, J. 1954. The construction of reality in the child. New York: Basic Books.

Posner, M. I., \& Petersen, S. E. 1990. The attention system of the human brain. Annual Review of Newroscience, 13, 25-42.

Roberts, R. J., \& Pennington, B. F. 1996. An interactive framework for examining prefrontal cognitive processes. Developmental Neuropsychology, 12, 105-126.

Thatcher, R. W. 1991. Maturation of the hurnan frontal lobes: Physiological evidence for staging. Developmental Neuropsychology, 7, 397-419.

Thatcher, R. W. 1994. Psychopathology of early frontal lobe damage: Dependence ou cycles of development. Development and Psychopathology, 6, 565-596.

Thatcher, R. W. 1997 . Human frontal lobe dewelopment: A theory of cyclical cortical reorganization. In N. A. Krasnegor, G. R. Lyon, \& P. S. Goldman-Rakic (Eds.), Development of the prefrontal cortex: Evolution, neurobiology, and behavior. Baltimore, MD: Brookes. Pp. 85-113.

Thatcher, R. W., Krause, P. J., \& Hrybyk, M. 1986. Cortico-cortical associalions and EEG coherence: A two compartmental model. Electroencephalography and Ctinical Neuro. physiology, 64, 123-143.

Thatcher, R. W., Walker, R. A., \& Giudice, S. 1987. Human cerebral hemispheres develop at different rates and ages. Science, 236, $1110-1113$.

Vclicer, W. F., Peacock, A. C., \& Jackson, D. N. 1982. A comparison of component and factor patterns: A Monte Carlo approach. Multivariate Behavioral Research 17, 371-
Wellman, H. M., Cross, D. \& Bartsch, K. 1986. Infant search and ofjettipermanence: A meta-analysis of the A-not.B error. In R. N. Enke (Ed.), Monographs of the Society for Research in Child Development, No. 214, Vol. 51. Chicago, IL: Univ of Chicago Press. R. 67 .

Welsh, M. C. \& Pennington, B. F. 1988. Assessing frontal lobe functioning in hildren: Views from developmental psychology. Devefopmental Psychology, 4, $199-230,3$

Welsh, M. C., Pennington, B. F., \& Groisser, D. B. 199l. A normative-developmental study of executive funclion: A window on prefrontal function in children. Developmental Nesropsychology, 7, 13I-149. 